\title{
Cross-Linked Low Molecular Weight Glycopeptide-Mediated Gene Delivery: Relationship between DNA Metabolic Stability and the Level of Transient Gene Expression In Vivo
}

\author{
YONGSHENG YANG, YOUMIE PARK, SHOUCHIN MAN, YAHONG LIU, KEVIN G. RICE \\ Departments of Medicinal Chemistry and Pharmaceutics, College of Pharmacy, University of Michigan, Ann Arbor, Michigan \\ 48109-1065
}

Received 10 April 2001; revised 15 June 2001; accepted 11 July 2001

\begin{abstract}
DNA co-condensates were formed by reacting $\left[{ }^{125} \mathrm{I}\right] \mathrm{DNA}$ with an admixture of a high-mannose glycopeptide $\left(\mathrm{Man} 9-\mathrm{CWK}_{18}\right.$ ) and either of two poly (ethylene glycol) peptides (PEG-VS-CWK 18 or PEG-SS-CWK 18 ) followed by crosslinking with 6-50 mol equiv of glutaraldehyde. $\left[{ }^{125} \mathrm{I}\right] \mathrm{DNA}$ co-condensates were administered intravenously in mice to determine the influence of peptide DNA formulation parameters on specific targeting to Kupffer cells. Optimal targeting to Kupffer cells required the combined use of $50 \mathrm{~mol} \% \mathrm{Man}_{-}-\mathrm{CWK}_{18}$ and PEG-CWK 18 to mediate specific recognition by the mannose receptor to Kupffer cells. The cellular uptake of cross-linked Man9-CWK 18 /PEG-CWK 18 DNA co-condensates was receptor mediated since Kupffer cell targeting was inhibited by pre-administration of Manbovine serum albumin (BSA) but not BSA. An optimized formulation targeted $60 \%$ of the dose to the liver, with $80 \%$ of the liver-targeted DNA localized to Kupffer cells. Crosslinking with either 6,15 , or 50 mol equiv of glutaraldehyde led to a corresponding decrease in the metabolism rate of DNA in liver as measured by half-live- of 4,6 , and $39 \mathrm{~h}$, respectively. Tail vein dosing of $50 \mu \mathrm{g}$ of DNA co-condensates cross-linked with $6 \mathrm{~mol}$ equiv of glutaraldehyde produced detectable levels of human $\alpha_{1}$-antitrypsin in blood after $12 \mathrm{~h}$, which peaked at day six and persisted for 10 days. The level of human $\alpha_{1}$-antitrypsin was elevated two-fold each day when dosing with DNA co-condensates cross-linked with 15 mol equiv of glutaraldehyde, revealing a correlation between the metabolic stability of the DNA in liver and level of gene expression. In addition to possessing greater metabolic stability, DNA co-condensates cross-linked with 50 mol equiv of glutaraldehyde, but lacking a targeting ligand, avoided rapid liver uptake and possessed a prolonged pharmacokinetic half-life, providing insight into a means to target DNA condensates to peripheral tissues. (c) 2001 Wiley-Liss, Inc. and the American Pharmaceutical Association J Pharm Sci 90:2010-2022, 2001
\end{abstract}

Keywords: biodistribution; pharmacokinetics; mannose receptor; glycopeptide; polyethylene glycol

\section{INTRODUCTION}

Polylysine has been derivatized with galactose, $N$ glycans, or glycoproteins to prepare carriers used to form DNA condensates that target the asialo-

Correspondence to: K.G. Rice (Telephone: 734-763-1032; Fax: 734-763-2022; E-mail: krice@umich.edu)

Journal of Pharmaceutical Sciences, Vol. 90, 2010-2022 (2001)

(c) 2001 Wiley-Liss, Inc. and the American Pharmaceutical Association glycoprotein receptor (ASGP-R) on hepatocytes and mediate transient gene expression in vivo. ${ }^{1-4}$ Although low levels of transient gene expression have been achieved in animals using these firstgeneration delivery carriers, both the level and duration of gene expression need to be significantly improved before intravenously dosed targeted nonviral gene delivery systems will have clinical utility. ${ }^{5}$ 
A plausible strategy to increase the level and duration of gene expression would be to block the metabolism rate of DNA delivered to tissues. In support of this proposal, one report found that the metabolic stability of asialoorosomucoid polylysine DNA condensates delivered to hepatocytes was extended from 1 to 7 days by performing a partial hepatectomy to increase the residence time of DNA in regenerating hepatocytes. ${ }^{6}$ Another study found that the metabolic rate of DNA in liver was decreased by substituting polyD-lysine for poly-L-lysine as a DNA carrier, illustrating that proteolysis plays a key step in the residence time of DNA in the target cell. ${ }^{7} \mathrm{~A}$ related report found that the duration of gene expression in vivo was related with the length of poly-L-lysine. ${ }^{8}$

In addition to the ASGP-R, the mannose receptor on Kupffer cells has been used as a model system to study transient gene expression in vivo. Ferkol et al. ${ }^{9}$ used mannosylated polylysine to form DNA condensates that targeted liver and spleen, mediating maximal luciferase expression at day 4 in spleen. In a subsequent paper, Ferkol et al. ${ }^{10}$ found that mannosylated polylysine DNA condensates targeted lung macrophages in rat and expressed detectable levels of human $\alpha_{1}$-antitrypsin (hAAT) at day 4 . Nishikawa et al. ${ }^{11}$ reported that mannosylated polylysine DNA condensates avoided entrapment in the lung and determined expression of chloramphenicol transferase in liver at $48 \mathrm{~h}$.

No prior studies have attempted to optimize carrier molecules to maximally protect DNA from metabolism and demonstrate how this influences the level or duration of gene expression. Low molecular weight (LMW, 20 amino acids or less) peptides have been proposed as replacements for high molecular weight (HMW) polylysine to allow systematic optimization of the gene delivery carrier. ${ }^{12-14}$ HMW polylysine can only be randomly derivatized, making it difficult to control the location and stoichiometry of poly(ethylene glycol)(PEG) or carbohydrate attached to the carrier molecule. ${ }^{15,16} \mathrm{LMW}$ peptides offer the advantages of being chemically defined and can be selectively derivatized with PEG or carbohydrate ligands. ${ }^{17,18}$ The stoichiometry of ligand may be controlled by forming DNA co-condensates from admixtures of LMW carriers possessing an identical peptide. ${ }^{17,18} \mathrm{~A}$ significant distinction between HMW and LMW peptide DNA condensates is the requirement of the latter to be stabilized by cross-linking to insure their survival during circulation and in the target tissue. $^{17}$

In the present study, LMW glycopeptide/PEGpeptide DNA co-condensates were formed and stabilized by glutaraldehyde cross-linking for the purpose of targeting Kupffer cells via the mannose receptor. Increasing the degree of crosslinking on DNA co-condensates revealed a relationship between the rate of DNA metabolism and the level of transient gene expression in vivo. In addition, the results demonstrate that highly stabilized DNA formulations circulate with a prolonged pharmacokinetic half-life. Controlling these parameters is fundamental to increasing the efficacy of nonviral gene delivery systems.

\section{MATERIALS AND METHODS}

Sodium ${ }^{125}$-I was purchased from Dupont NEN, Boston, MA. Heparin, D-mannitol, thallium trichloride, sodium sulfite, potassium iodine, mannosylated bovine serum albumin (Man-BSA) bovine serum albumin (BSA), Hepes, collagenase from clostridium histolyticum type IV, carbonyl iron, $70 \%$ glutaraldehyde, 2,2'-azion-bis(3-ethylbenzthiaxoline-6-sulfonic acid (ABTS), Tween 20, antihuman $\alpha_{1}$-antitrypsin IgG from goat and rabbit, and human $\alpha_{1}$-antitrypsin were purchased from Sigma, St. Louis, MO. Hydrogen peroxide (3\%) was purchased from Aldrich, Milwaukee, WI. Agarose was purchased from Gibco-BRL, Gaithersburg, MD. Poly(ethylene glycol)-orthopyridyl disulfide (PEG-OPSS, $5 \mathrm{kDa}$ ) was purchased from Shearwater Inc., Huntswille, AL. Poly(ethylene glycol)-vinyl sulfone (PEG-VS, $5 \mathrm{kDa}$ ) was purchased from Fluka, Ronkonkoma, NY. Ketamine hydrochloride was purchased from Fort Dodge Laboratories, Fort Dodge, IA. Xylazine hydrochloride was purchased from Miles Inc., Shawnee Mission, KS. Silastic catheters $(0.305 \mathrm{~mm}$ inner diameter $\times 0.635 \mathrm{~mm}$ outer diameter) were purchased from Baxter, Obetz, OH. ICR mice (30$35 \mathrm{~g})$ purchased from Harlan, Indianapolis, IN, and housed in cages located in a limited access area with a 12-h light-dark cycle and controlled temperature $\left(26-28^{\circ} \mathrm{C}\right)$. Ultrapure $100 \mathrm{DNA}$ purification columns were purchased from Qiagen, Santa Clarita, CA. Analytical and semi-preparative high-performance liquid chromatography (HPLC) columns were purchased from Vydac, Hesperia, CA. 


\section{Radiolabeling Plasmid DNA}

Endotoxin-free plasmid DNA encoding hAAT under transcriptional control of the cytomegalovirus promoter (pCMVhAAT) ${ }^{19}$ was purified from $E$. coli with a Qiagen ultrapure column according to the manufacturer. Plasmid DNA was radiolabeled with ${ }^{125} \mathrm{I}$ as described previously, ${ }^{20}$ resulting in supercoiled and circular DNA with specific activity ranging from 300 to $450 \mathrm{nCi} / \mu \mathrm{g}$.

\section{Glycopeptide and PEG-Peptide Synthesis}

$\mathrm{CWK}_{18}$ (Cys-Trp-Lys ${ }_{18}$ ) was synthesized on a solid support and purified as previously reported..$^{21}$ The terminal cysteine was either alkylated $\left(\mathrm{AlkCWK}_{18}\right)$ with iodoacetic acid or used as an $N$-glycan or PEG attachment site. A highmannose $N$-glycan was purified from soy bean agglutinin as the Boc-tyrosinamide derivative (Man9). ${ }^{22}$ Man9 was converted to an iodoacetylated tyrosinamide oligosaccharide then reacted with $\mathrm{CWK}_{18}$ to form Man9-CWK $18 .{ }^{17}$ PEG-VS$\mathrm{CWK}_{18}$ and PEG-SS-CWK 18 were prepared as reported previously. ${ }^{18}$ Man9-CWK 18 , PEG$\mathrm{CWK}_{18}$, and $\mathrm{AlkCWK}_{18}$ stock solutions were quantified by absorbance $\left(\varepsilon_{280 \mathrm{~nm}}=5600 \mathrm{M}^{-1} \mathrm{~cm}^{-1}\right.$ for Trp in PEG-peptides and $\mathrm{AlkCWK}_{18}$, $\varepsilon_{280 \mathrm{~nm}}=6930 \mathrm{M}^{-1} \mathrm{~cm}^{-1}$ for Trp and Tyr in Man9-CWK 18 ).

\section{Formulation of Glycopeptide/PEG-Peptide DNA Co-Condensates}

Man9-CWK ${ }_{18}$ was combined with either PEG-VS$\mathrm{CWK}_{18}$ or PEG-SS-CWK 18 to form a $40 \mathrm{nmol} / \mathrm{mL}$ admixture of $2: 98,10: 90$, or 50:50 mol \% Man9$\mathrm{CWK}_{18} /$ PEG-CWK 18 in $5 \mathrm{mM}$ Hepes, $0.27 \mathrm{M}$ mannitol pH 7.4 (HBM). DNA co-condensates were formed by combining glycopeptide/PEGpeptide admixtures with an equal volume of $100 \mu \mathrm{g} / \mathrm{mL}$ pCMVhAAT in HBM while vortexing, which results in $50 \mu \mathrm{g} / \mathrm{mL}$ DNA co-condensates prepared at a stoichiometry of $0.4 \mathrm{nmol}$ of peptide per microgram of DNA or a charge ratio $\left(\mathrm{NH}_{4}^{+} /\right.$ $\mathrm{PO}_{4}^{-}$) of 2.4:1. DNA co-condensates formed instantly but were allowed to equilibrate for $30 \mathrm{~min}$ prior to cross-linking.

Cross-linked DNA co-condensates were formed by adding 12,30 , or $100 \mu \mathrm{g}$ of glutaraldehyde to $1 \mathrm{~mL}$ of preformed $50 \mu \mathrm{g} / \mathrm{mL}$ DNA co-condensates, which corresponds to 6,15 , and $50 \mathrm{~mol}$ equiv relative to $1 \mathrm{~mol}$ equiv of peptide, followed by reaction for $12 \mathrm{~h}$ at $4^{\circ} \mathrm{C}^{23}$ After cross-linking, the particle size (quasi-elastic light scattering; QELS) and zeta potential were analyzed on a Zeta-Plus (Brookhaven Instruments, Co, Holtsville, NY).

\section{Biodistribution and Pharmacokinetic Analysis of Cross-Linked DNA Co-Condensates}

Biodistribution analysis was performed by inserting a single catheter in the right jugular vein of three anesthetized mice. Cross-linked DNA cocondensates $\left(2.5 \mu \mathrm{g}\right.$ of ${ }^{125} \mathrm{I}-\mathrm{DNA}, 1.0 \mu \mathrm{Ci}$, in $50 \mu \mathrm{L}$ $\mathrm{HBM}$ ), were dosed iv followed by vein ligation. At times ranging from 5 to $360 \mathrm{~min}$, mice were sacrificed by cervical dislocation, and the major organs (liver, lung, spleen, stomach, kidney, heart, large intestine, and small intestine) were harvested, rinsed with saline, and weighed. Longer term biodistribution was analyzed by dosing mice via the tail vein. At 1-3 days, mice were anesthetized, sacrificed by cervical dislocation, and dissected as already described. The radioactivity in each organ was determined by direct gamma counting and expressed as the targeting efficiency, which is defined as the percent of the dose in the target organ.

Pharmacokinetic analysis was performed by inserting dual jugular vein cannula into anesthetized mice. $\left[{ }^{125} \mathrm{I}\right] \mathrm{DNA}$ formulations were dosed in the left vein, and $10-\mu \mathrm{L}$ samples of blood were taken at $1,3,6,10,15,20,30,40,60,90,120$, and 180 min time points from the right vein followed by replacement with normal saline. The radioactivity (cpm) at each time point from triplicate mice was determined by direct gamma counting. The data were fit to a two-compartment model using PCNONLIN. ${ }^{24}$

\section{Cellular Distribution of Cross-Linked DNA Co-Condensates in Liver}

Mice were dosed iv in the tail vein with $20 \mathrm{mg}$ of carbonyl iron in $0.2 \mathrm{~mL}$ of saline. After $45 \mathrm{~min}$, mice were anesthetized, and a single catheter was inserted into the right jugular vein and used to dose cross-linked DNA co-condensates $(2.5 \mu \mathrm{g}$ of $\left[{ }^{125}\right] \mathrm{DNA}, 1 \mu \mathrm{Ci}$, in $50 \mu \mathrm{L}$ of $\left.\mathrm{HBM}\right)$. For receptor blocking experiments, mice were dosed with $3.5 \mathrm{mg}$ of Man-BSA or BSA in $100 \mu \mathrm{L}$ of saline 1 min prior to dosing DNA formulations. After a 30-min biodistribution, the portal vein was cannulated and used to administer $0.2 \mathrm{~mL}$ of heparin $(100 \mathrm{U} / \mathrm{mL})$ followed immediately by the perfusion buffer. The liver was first perfused at $5 \mathrm{~mL} / \mathrm{min}$ for 2 min with oxygenated $(95 \%$ oxygen, $5 \%$ 
carbon dioxide) preperfusion buffer (calcium- and magnesium-free Hepes solution, $\mathrm{pH} 7.45,37^{\circ} \mathrm{C}$ ), and then at a rate of $3 \mathrm{~mL} / \mathrm{min}$ for an additional $3 \mathrm{~min}$. The perfusion was continued for $16-20 \mathrm{~min}$ at $3 \mathrm{~mL} / \mathrm{min}$ with oxygenated Seglen's Buffer $(\mathrm{pH}$ $\left.7.45,37^{\circ} \mathrm{C}\right)$ containing $0.058 \%(\mathrm{w} / \mathrm{v})$ collagenase type IV. At the start of the perfusion the vena cava and aorta were cut, and at the completion, the liver was excised and placed in a Petri dish $\left(4^{\circ} \mathrm{C}\right)$ and cut into small pieces. Cells were dislodged and dispersed in ice-cold Hank's (containing $10 \mathrm{mM}$ Hepes, $\mathrm{pH} 7.45,0.1 \% \mathrm{BSA}$ ) and then incubated at $37^{\circ} \mathrm{C}$ for $20 \mathrm{~min}$ with shaking (30 rpm). The dispersed cells were filtered through a $73-\mu \mathrm{m}$ mesh filter, then transferred to a $35-\mathrm{mL}$ glass tube. The iron-filled Kupffer cells were attracted to the wall of the tube with a magnet, whereas the other cells were decanted off. The procedure was repeated three times, and the Kupffer cells were combined and resuspended in $0.8 \mathrm{~mL}$ of Hanks Hepes Buffer. The remaining suspension was centrifuged at $50 \mathrm{~g}$ for $1 \mathrm{~min}$, and the supernatant was discarded. The pelleted hepatocytes were washed two times with ice-cold Hank's-Hepes buffer followed by centrifuging at $50 \mathrm{~g}$ for $1 \mathrm{~min}$. Purified hepatocytes were resuspended in $2 \mathrm{~mL}$ of Hank's-Hepes buffer. The cell purity $(>90 \%)$ and number $\left(6 \times 10^{6}\right.$ hepatocytes and $4.8 \times 10^{5}$ Kupffer cells) were determined with a hemocytometer, and cell viability $(>90 \%)$ was determined by the trypan blue exclusion test. The radioactive DNA in each cell fraction was measured by gamma counting.

\section{In Vivo Gene Expression}

Mice were dosed iv via the tail vein by infusing $1 \mathrm{~mL}$ of $50 \mu \mathrm{g} / \mathrm{mL}$ cross-linked DNA co-condensates over a period of $10 \mathrm{~min}$. Blood was harvested $(1 \mathrm{~mL}$ ) from 3 mice at $12 \mathrm{~h}$ and each day for 10 days after dosing. The blood was allowed to clot at room temperature and was centrifuged at $13,000 \mathrm{~g}$ for $15 \mathrm{~min}$. The serum was stored at $-20^{\circ} \mathrm{C}$ until assayed by ELISA.

A modified double antibody sandwich ELISA was used to determine the magnitude of human alpha-1 antitrypsin (hAAT) gene expression. ${ }^{25}$ The primary antibody (goat anti-hAAT) was diluted 1:1000 in $0.1 \mathrm{M}$ sodium bicarbonate (pH 9.6), added $(100 \mu \mathrm{L})$ to each well, and incubated overnight at $4^{\circ} \mathrm{C}$. Nonspecific binding was blocked with $100 \mu \mathrm{L}$ of $5 \mathrm{w} / \mathrm{v} \%$ non-fat dry milk in PBS for $1 \mathrm{~h}$ at $37^{\circ} \mathrm{C}$. Mouse serum samples $(100 \mu \mathrm{L})$ or standards were added to each well and allowed to bind for $2 \mathrm{~h}$ at $37^{\circ} \mathrm{C}$. The secondary antibody (rabbit anti-hAAT) was diluted 1:1000 in PBS-Tween, added $(100 \mu \mathrm{L})$ to each well, and incubated at $37^{\circ} \mathrm{C}$ for $2 \mathrm{~h}$. Anti-rabbit peroxidase conjugated antibody $(100 \mu \mathrm{L})$ diluted 1:1000 in PBS-Tween was added and allowed to bind for $2 \mathrm{~h}$ at room temperature. Finally, substrate solution $(100 \mu \mathrm{L}$ of $1 \mathrm{mg} / \mathrm{mL}$ ABTS in $0.2 \mathrm{M}$ phosphate buffer, $\mathrm{pH} 7.6$, with $0.003 \%$ hydrogen peroxide) was added and incubated at room temperature for $2 \mathrm{~h}$. After $30 \mathrm{~min}$, the absorbance at $415 \mathrm{~nm}$ was measured on a BioRad 550 microplate reader. The amount of hAAT expressed was determined by comparison to a triplicate standard curve of hAAT prepared in blank mouse serum.

\section{RESULTS}

Based on the hypothesis that DNA metabolism is likely to influence the level and duration of transient gene expression in vivo, we developed a formulation that allows systematic control over this parameter. The three components of the gene delivery system are (1) a chemically defined LMW glycopeptide and PEG-peptide, (2) a plasmid encoding hAAT, and (3) a cross-linking agent to stabilize DNA co-condensates.

LMW carriers were prepared by reacting the Cys residue on $\mathrm{CWK}_{18}$ with either a single poly(ethylene glycol) chain to form PEG-VS$\mathrm{CWK}_{18}$ or PEG-SS-CWK 18 an $N$-glycan to form Man9-CWK ${ }_{18}$, or iodoacetic acid to form AlkCWK $_{18}$ (Figure 1). PEG-peptides were used to block serum protein and cell surface binding by forming a hydrophilic layer on the surface of DNA condensates. ${ }^{26}$ A high-mannose glycopeptide (Man9-CWK ${ }_{18}$ ) was used to mediate targeting to the mannose receptor found on the surface of Kupffer cells, ${ }^{27}$ and $\mathrm{AlkCWK}_{18}$ was substituted for Man9-CWK $\mathrm{CW}_{18}$ in control formulations.

Man9-CWK 18 (or AlkCWK 18 )/PEG-peptide admixtures were used to form DNA co-condensates according to Scheme 1 in which the admixture ratio controlled the stoichiometry of peptide conjugates bound to DNA. ${ }^{26}$ In the final step, glutaraldehyde was used to cross-link DNA cocondensates by di-Schiffs base formation between amine groups on neighboring glycopeptides and PEG-peptides bound to DNA. ${ }^{17}$

To maximize the targeting of DNA to Kupffer cells, the admixture ratio of Man9-CWK 18 and PEG-VS-CWK 18 was varied while keeping the glutaraldehyde cross-linking constant at 15 


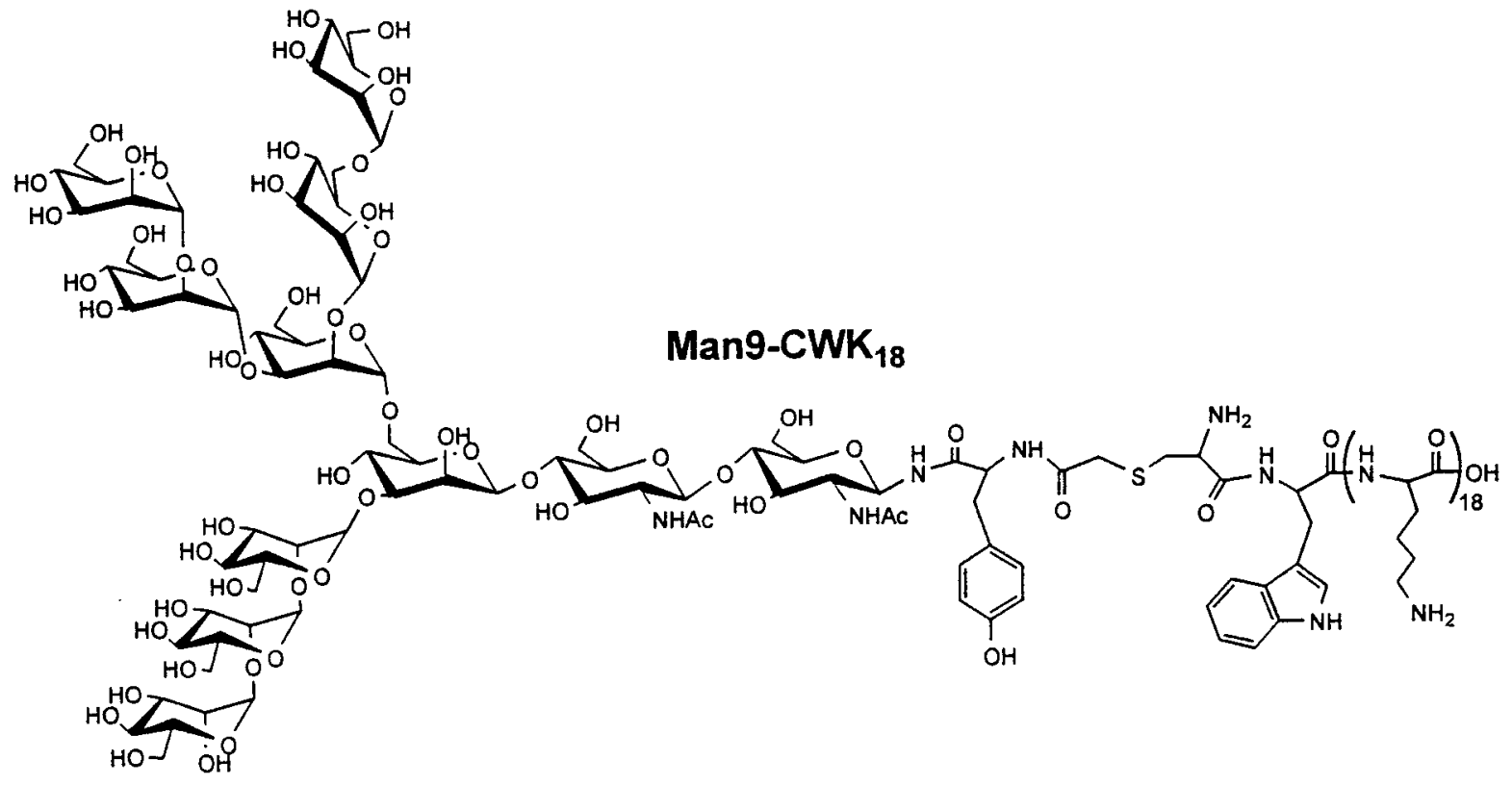

PEG-VS-CWK 18<smiles></smiles>

\section{PEG-SS-CWK 18}<smiles>COCCOC(C)(C)CSSCC(N)C(=O)NC(Cc1c[nH]c2ccccc12)C(C)=O</smiles><smiles>NCCCC(NC(=O)C(Cc1c[nH]c2ccccc12)NC(=O)C(N)CSCC(=O)O)C(=O)O</smiles>

Figure 1. Structure of Man9-CWK 18 , PEG-VS-CWK 18, PEG-SS-CWK 18 , and AlkCWK ${ }_{18}$. The chemical structure of each LMW DNA condensing peptide used is illustrated. Each conjugate shares a common 20 amino acid peptide $\left(\mathrm{CWK}_{18}\right)$ but differs in the composition of the polymer attached to the cysteine residue. 


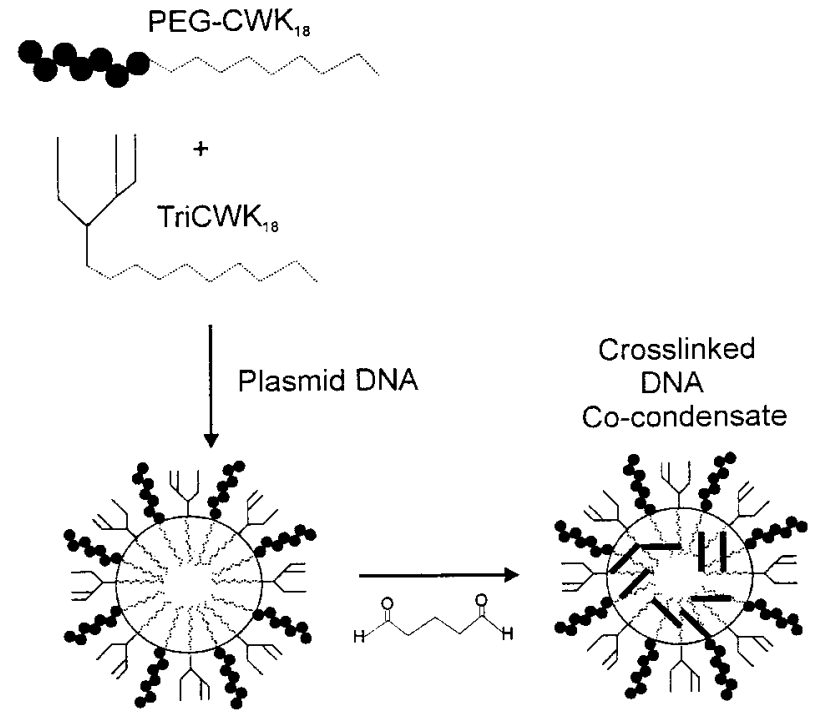

Scheme 1. Preparation of glutaraldehyde crosslinked DNA co-condensates. DNA co-condensates formed by reaction of plasmid DNA with an admixture of PEG-CWK 18 and Man9-CWK 18 are stabilized with glutaraldehyde to cross-link residual amino groups. Both the admixture ratio and glutaraldehyde crosslinking level are systematically varied to optimize Kupffer cell targeting and gene expression.

equiv. Prior to in vivo analysis, each DNA formulation was analyzed for particle size and zeta potential (Table 1). Formulations prepared at admixture ratios of 2:98, 10:90, and 50:50 mol \% Man9-CWK $_{18} /$ PEG-CWK $_{18}$ possessed a mean particle size ranging from 95 to $120 \mathrm{~nm}$ and a surface charge of $+3-11 \mathrm{mV}$ (Table 1, C-E). Substitution of PEG-VS-CWK 18 with PEG-SS$\mathrm{CWK}_{18}$ did not influence the size or charge of the DNA co-condensates (Table $1, \mathrm{E}$ versus $\mathrm{F}$ ). However, a progressive increase in the mean particle size occurred for DNA condensates prepared with increasing glutaraldehyde cross-linking (Table 1, E, G-J).

Biodistribution and pharmacokinetic analysis of cross-linked DNA co-condensates utilized ${ }^{125} \mathrm{I}$ labeled plasmid DNA as a tracer to quantitatively monitor the radioactivity in blood and tissues over time. Intravenously dosed ${ }^{125}$ I-plasmid DNA rapidly, distributes, with $60 \%$ of dose recovered in the liver after $5 \mathrm{~min}$, as reported previously. ${ }^{17}$ Of the liver targeted DNA, 65\% was recovered in Kupffer cells, with the remaining 35\% associated with hepatocytes (Figure 2A). By comparison, the nonspecific biodistribution of a control formulation composed of cross-linked (15 equiv) $50 \mathrm{~mol} \%$ AlkCWK $_{18} /$ PEG-VS-CWK 18 DNA co-condensates
Table 1. Particle Size and Zeta Potential of DNA Formulations $^{a}$

\begin{tabular}{lcc}
\hline $\begin{array}{l}\text { Dosage } \\
\text { Form }\end{array}$ & $\begin{array}{c}\text { Particle Size } \\
(\mathrm{nm})\end{array}$ & $\begin{array}{c}\text { Zeta Potential }^{c} \\
(+\mathrm{mV})\end{array}$ \\
\hline A & $116 \pm 7$ & $10.2 \pm 1.6$ \\
B & $103 \pm 15$ & $1.5 \pm 0.5$ \\
C & $95 \pm 10$ & $4.4 \pm 0.7$ \\
D & $109 \pm 13$ & $3.4 \pm 1.0$ \\
E & $120 \pm 9$ & $11.4 \pm 2.2$ \\
F & $118 \pm 6$ & $8.6 \pm 3.0$ \\
G & $101 \pm 26$ & $4.6 \pm 1.0$ \\
H & $194 \pm 5$ & $3.6 \pm 1.4$ \\
I & $322 \pm 24$ & $6.8 \pm 2.0$ \\
J & $383 \pm 7$ & $6.4 \pm 1.4$ \\
\hline
\end{tabular}

${ }^{a}$ Each formulation was prepared at a DNA concentration of $50 \mu \mathrm{g} / \mathrm{mL}$, at a stoichiometry of $0.4 \mathrm{nmol}$ of total peptide per microgram of DNA, and a charge ratio of 2.4:1.

${ }^{b}$ Particle size is reported as the mean diameter and standard deviation of three measurements.

${ }^{c}$ Zeta potential is reported as the mean and standard deviation of 10 measurements: $\mathrm{A}=$ cross-linked (15 equiv) $\mathrm{AlkCWK}_{18} / \mathrm{PEG}-\mathrm{VS}-\mathrm{CWK}_{18}$ (50:50); $\mathrm{B}=$ cross-linked (15 equiv) $\mathrm{PEG} \mathrm{VS}-\mathrm{CWK}_{18}$ (100); $\mathrm{C}=$ cross linked (15 equiv) Man9$\mathrm{CWK}_{18}$ /PEG-VS-CWK 18 (2:98); $\mathrm{D}=$ cross-linked (15 equiv) Man9-CWK ${ }_{18}$ PEG/VS-CWK 18 (10:90); $\quad \mathrm{E}=$ cross-linked (15 equiv) Man9-CWK 18 PEG-VS-CWK 18 (50:50); $\mathrm{F}=$ crosslinked (15 equiv) Man9-CWK $18 /$ PEG-SS-CWK 18 (50:50); $\mathrm{G}=$ cross-linked $\quad\left(6\right.$ equiv) Man9-CWK $_{18} / \mathrm{PEG} \mathrm{VS}-\mathrm{CWK}_{18}$ (50:50); $\mathrm{H}=$ cross-linked (20 equiv) $\mathrm{Man} 9-\mathrm{CWK}_{18} / \mathrm{PEG}-\mathrm{VS}-$ $\mathrm{CWK}_{18}$ (50:50); I = cross-linked (30 equiv) Man9-CWK 18 / PEG-VS-CWK 18 (50:50); $\mathrm{J}=$ cross-linked (50 equiv) Man9$\mathrm{CWK}_{18} /$ PEG-VS-CWK 18 (50:50).

revealed $53 \%$ targeted to hepatocytes and $47 \%$ to Kupffer cells (Figure 2B). This formulation, which lacked a targeting ligand but possessed comparable particle size and surface charge relative to experimental formulations (Table 1), was used as a reference point to determine the influence of Man9-CWK ${ }_{18}$ on mediating Kupffer cell targeting. Likewise, a second control formulation of cross-linked (15 equiv) $100 \mathrm{~mol} \%$ PEG-VS-CWK 18 DNA condensates distributed with $41 \%$ targeting hepatocytes and 59\% to Kupffer cells.

A significant improvement in selectivity was afforded when using $2 \mathrm{~mol} \%$ of Man9-CWK 18 and 98 mol \% PEG-VS-CWK 18 , resulting in $61 \%$ recovery in Kupffer cells and 39\% in hepatocytes (Figure 2D). Increasing the ratio of Man9-CWK 18 to $10 \mathrm{~mol} \%$ resulted in an increase in selectivity with $68 \%$ targeting to Kupffer cells and $32 \%$ to hepatocytes (Figure 2E). Likewise, 50 mol Man9CWK $_{18}$ increased the Kupffer cell targeting selectivity to $80 \%$ (Figure $2 \mathrm{~F}$ ), whereas increasing Man9-CWK 18 to $75 \mathrm{~mol} \%$ failed to further improve the Kupffer cell targeting selectivity (Figure 2G). Substituting PEG-SS-CWK 18 for 


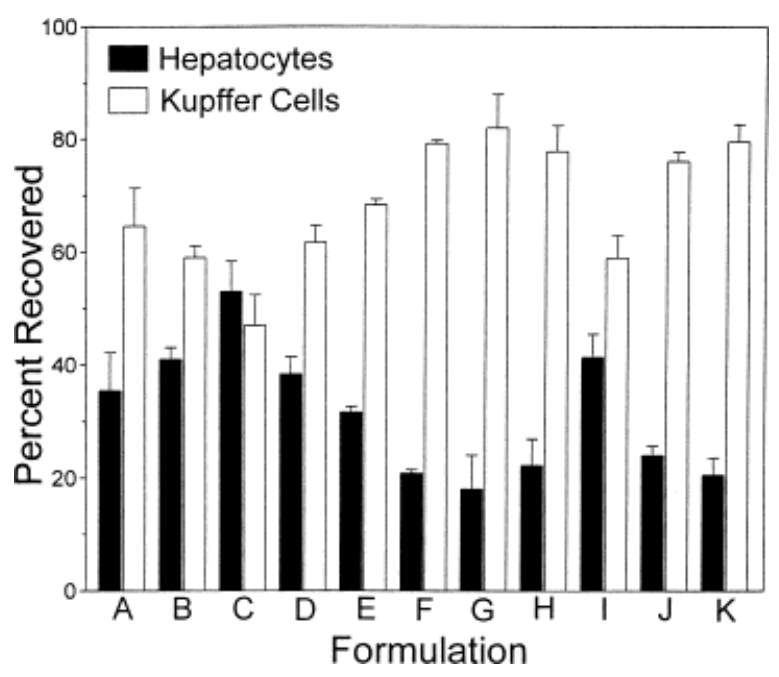

Figure 2. Cell-type specific targeting of cross-linked DNA co-condensates. The ratio of $\left[{ }^{125} \mathrm{I}\right] \mathrm{DNA}$ recovered from hepatocytes and Kupffer cells following iv dosing of different formulations is illustrated. The formulations studied are (A) ${ }^{125}$ I-plasmid DNA; (B) cross-linked (15 equiv) AlkCWK 18 PEG-VS-CWK 18 (50:50 mol \%); (C) cross-linked (15 equiv) PEG-VS-CWK ${ }_{18}(100 \mathrm{~mol} \%$ ); (D) cross-linked (15 equiv) Man9-CWK 18 PEG-VS$\mathrm{CWK}_{18}(2: 98 \mathrm{~mol} \%)$; (E) cross-linked (15 equiv) Man9-CWK $_{18} /$ PEG-VS-CWK $18 \quad(10: 90$ mol \%); (F) cross-linked (15 equiv) Man9-CWK 18 PEG-VS-CWK 18 (50:50 mol \%); (G) cross-linked (15 equiv) Man9-CWK 18 / PEG-VS-CWK 18 (75:25 mol \%); (H) cross-linked (15 equiv) Man9-CWK 18 PEG-SS-CWK 18 (50:50 mol $\%)$; (I) cross-linked (15 equiv) Man9-CWK $18 /$ PEG-VS$\mathrm{CWK}_{18}(50: 50 \mathrm{~mol} \%)$ administered after $3.5 \mathrm{mg}$ of Man-BSA; (J) cross-linked (15 equiv) Man9-CWK 18 / PEG-VS-CWK 18 (50:50 mol \%) administered after $3.5 \mathrm{mg}$ of BSA; (K) cross-linked (50 equiv) Man9$\mathrm{CWK}_{18} / \mathrm{PEG}-\mathrm{VS}-\mathrm{CWK}_{18}(50: 50 \mathrm{~mol} \%)$. Each bar represents the mean and standard deviation of three independent measurements.

PEG-VS-CWK 18 in 50 mol \% Man9-CWK MNA $_{18}$ DNA co-condensates also did not influence the Kupffer cell targeting selectivity (Figure $2 \mathrm{H}$ ), suggesting that the disulfide bond linking PEG and $\mathrm{CWK}_{18}$ is not significantly reduced during circulation.

To support the hypothesis that the Kupffer cell targeting was mediated by the mannose receptor, $3.5 \mathrm{mg}$ (50 mol excess based on mannose) of Man-BSA was administered prior to dosing crosslinked $50 \mathrm{~mol} \% \mathrm{Man}_{-}-\mathrm{CWK}_{18} / \mathrm{PEG}-\mathrm{VS}-\mathrm{CWK}_{18}$ DNA co-condensates. This procedure effectively blocked reduced cell targeting from 80 to 59\% (Figure 2I), whereas a control experiment, substituting BSA for Man-BSA failed to reduced Kupffer cell targeting (Figure 2J).
Comparison of otherwise identical formulations possessing 15 and 50 equiv cross-linking resulted in $\sim 80 \%$ targeting to Kupffer cells, establishing that the level of glutaraldehyde cross-linking did not alter Kupffer cell targeting selectivity (Figure $2 \mathrm{~F}$ versus $\mathrm{K}$ ). Finally, dose escalation from 2.5 to $50 \mu \mathrm{g}$ of cross-linked (15 equiv) $50 \mathrm{~mol} \%$ Man9-CWK 18 PEG-VS$\mathrm{CWK}_{18}$ DNA co-condensates administered either via the jugular vein $(2.5 \mu \mathrm{g})$ or tail vein $(50 \mu \mathrm{g})$ established that neither the dosing location nor DNA quantity significantly altered Kupffer cell targeting selectivity (not shown).

A 60-min tissue biodistribution profile for cross-linked (6, 15 , or 50 equiv) $50 \mathrm{~mol} \%$ Man9$\mathrm{CWK}_{18} / \mathrm{PEG}-\mathrm{VS}-\mathrm{CWK}_{18}$ DNA co-condensates demonstrated the influence of cross-linking level on DNA tissue biodistribution (Figure 3A-C). Depending on cross-linking level, $\sim 5-10 \%$ of the DNA targeted to lung, with $10-25 \%$ targeted to spleen and only trace quantities $(<2 \%)$ detected in other organs. At each cross-linking level, the majority of the radioactivity was recovered in liver (39-61\%), which increased with increasing cross-linking level, reaching $61 \%$ when using 50 equiv of glutaraldehyde.

The total radioactivity recovered from tissues following a 60-min biodistribution was $62 \%$ when cross-linked with 6 equiv of glutaraldehyde (Figure 3A, open bar). This amount increased to 91\% when using 15 equiv (Figure 3B, open bar) of glutaraldehyde and nearly $100 \%$ when cross-linking with 50 equiv of glutaraldehyde (Figure 3C, open bar). The unaccounted radioactivity at lower cross-linking levels was recovered in blood or excreted into the urine as discussed in greater detail later.

Analysis of the biodistribution over time revealed a correlation between the level of glutaraldehyde cross-linking and the elimination rate of DNA from liver $\left(t_{1 / 2}\right.$, Figure 4$)$. With glutaraldehyde cross-linking of 6 equiv, the $t_{1 / 2}$ was $\sim 4-5 \mathrm{~h}$ for DNA formulations composed of either $50 \mathrm{~mol}$ $\%$ AlkCWK $_{18} /$ PEG-VS-CWK $_{18}$ (Figure 4A), Man9$\mathrm{CWK}_{18} / \mathrm{PEG}-\mathrm{VS}-\mathrm{CWK}_{18}$ (Figure $4 \mathrm{D}$ ), or Man9$\mathrm{CWK}_{18} /$ PEG-SS-CWK 18 (Figure 4G). Increasing the glutaraldehyde cross-linking to 15 equiv increased the $t_{1 / 2}$ to $6-11 \mathrm{~h}$ (Figures $4 \mathrm{~B}, \mathrm{E}$ and $\mathrm{H})$, for each formulation whereas cross-linking with 50 equiv of glutaraldehyde produced a very long $t_{1 / 2}$ that ranged from 39 to $83 \mathrm{~h}$ for each formulation (Figures 4C, E, and I).

Analysis of the early biodistribution profile revealed that the liver-targeting efficiency reached 


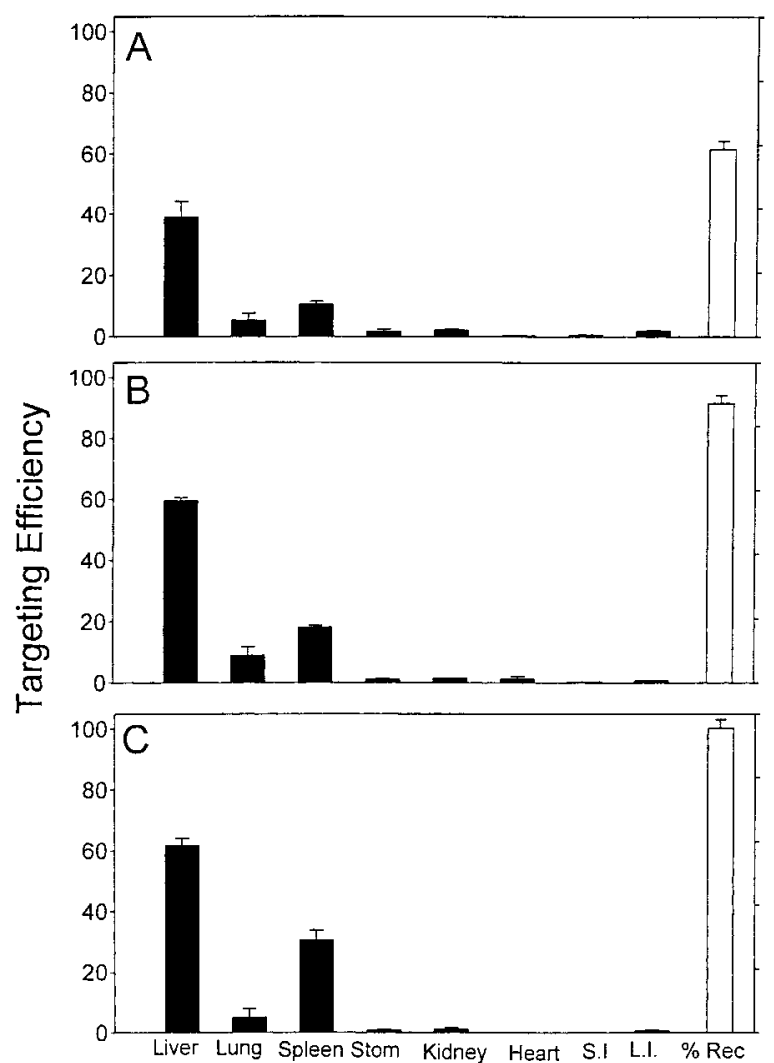

Figure 3. Tissue biodistribution of $\left[{ }^{125} \mathrm{I}\right] \mathrm{DNA}$ formulations in mice. The 60 -min tissue biodistribution of iv dosed cross-linked $(6,15$, and 50 equiv) Man9-CWK 18 / PEG-VS-CWK 18 (50 mol \%) [ $\left.{ }^{125} \mathrm{I}\right] \mathrm{DNA}$ co-condensates in mice are illustrated. Panels $\mathrm{A}, \mathrm{B}$, and $\mathrm{C}$, illustrate the targeting efficiency (\% of dose) for formulations crosslinked with 6,15 , and 50 equiv of glutaraldehyde respectively. The open bar in each panel represent the total recovery of radioactivity in the tissues. Each result represents the mean and standard deviation of three independent analysis.

a maximum of $40-60 \%$ at $30 \mathrm{~min}$, with 6 equiv cross-linking (Figures 4A, D, and G, insets), followed by a rapid decline to nearly zero at $24 \mathrm{~h}$. Increasing the cross-linking to 15 equiv also produced a maximal liver-targeting efficiency of $40-60 \%$ at $30 \mathrm{~min}$ that declined more slowly as a result of decreased metabolism (Figures 4B, E, and $\mathrm{H}$ insets). Cross-linking with 50 equiv of glutaraldehyde had the effect of decreasing the initial liver-targeting efficiency at $5 \mathrm{~min}$ to $27-35 \%$. This result was followed by glutaraldehyde accumulation in the liver over time to reach $40-60 \%$ at 60 min, which plateaued at a maximum of nearly $60-70 \%$ after $4 \mathrm{~h}$ and then proceeded on a slow decline due to metabolism (Figures 4C, E, and I, insets).

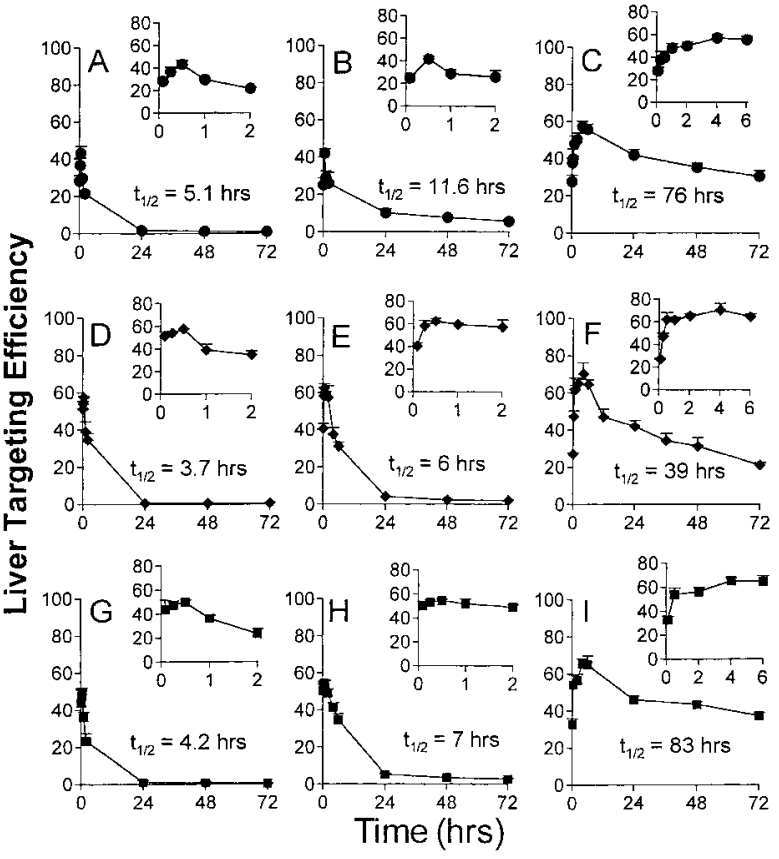

Figure 4. Liver biodistribution profile for $\left[{ }^{125} \mathrm{I}\right] \mathrm{DNA}$ formulations in mice. The time course of liver targeting and elimination of iv dosed $\left[{ }^{125} \mathrm{I}\right] \mathrm{DNA}$ formulations in mice are illustrated. Each panel illustrates the targeting efficiency ( $\%$ of dose in liver) determined over 3 days following a single iv dose. The insets in each panel expand the early biodistribution during $0-2$ or $0-6 \mathrm{~h}$. The calculated half-life $\left(t_{1 / 2}\right)$ of DNA in the liver is indicated in each panel. Panel A, B, and $\mathrm{C}$ represent $50 \mathrm{~mol} \% \mathrm{AlkCWK}_{18} / \mathrm{PEG}-\mathrm{VS}-\mathrm{CWK}_{18}\left[{ }^{125} \mathrm{I}\right] \mathrm{DNA}$ cocondensates cross-linked with 6,15 or 50 equiv of glutaraldehyde, respectively. Panels $\mathrm{D}, \mathrm{E}$, and $\mathrm{F}$ represent $50 \mathrm{~mol} \% \mathrm{Man}_{-}-\mathrm{CWK}_{18} / \mathrm{PEG}-\mathrm{VS}-\mathrm{CWK}_{18}$ $\left[{ }^{125} \mathrm{I}\right] \mathrm{DNA}$ co-condensates cross-linked with 6,15 , or 50 equiv of glutaraldehyde, respectively. By comparison, Panels G, H, and I represent 50 mol \% Man9$\mathrm{CWK}_{18} / \mathrm{PEG}-\mathrm{SS}-\mathrm{CWK} \mathrm{H}_{18} \quad\left[{ }^{125} \mathrm{I}\right] \mathrm{DNA} \quad$ co-condensates cross-linked with 6,15 , or 50 equiv of glutaraldehyde, respectively. Each result represents the mean and standard deviation of three independent analysis.

The lag time in the liver accumulation of $\left[{ }^{125} \mathrm{I}\right] \mathrm{DNA}$ co-condensates using 50 equiv of glutaraldehyde cross-linking was assumed to be the result of an increase in the circulatory half-life $\left(\alpha t_{1 / 2}\right)$. To investigate this hypothesis, the pharmacokinetics of DNA co-condensates prepared as either 50 mol \% Man9-CWK 18 /PEG-VS$\mathrm{CWK}_{18}$ or $\mathrm{AlkCWK}_{18} / \mathrm{PEG}-\mathrm{VS}-\mathrm{CWK}_{18}$, stabilized with either 6 or 50 equiv of glutaraldehyde, were compared. Cross-linked (6 equiv) $50 \mathrm{~mol} \%$ Man9$\mathrm{CWK}_{18} / \mathrm{PEG}-\mathrm{VS}-\mathrm{CWK}_{18} \quad\left[{ }^{125} \mathrm{I}\right] \mathrm{DNA}$ co-condensates produced a short $\alpha t_{1 / 2}$, which ended abruptly at $15 \mathrm{~min}$ and led to a steady-state level 


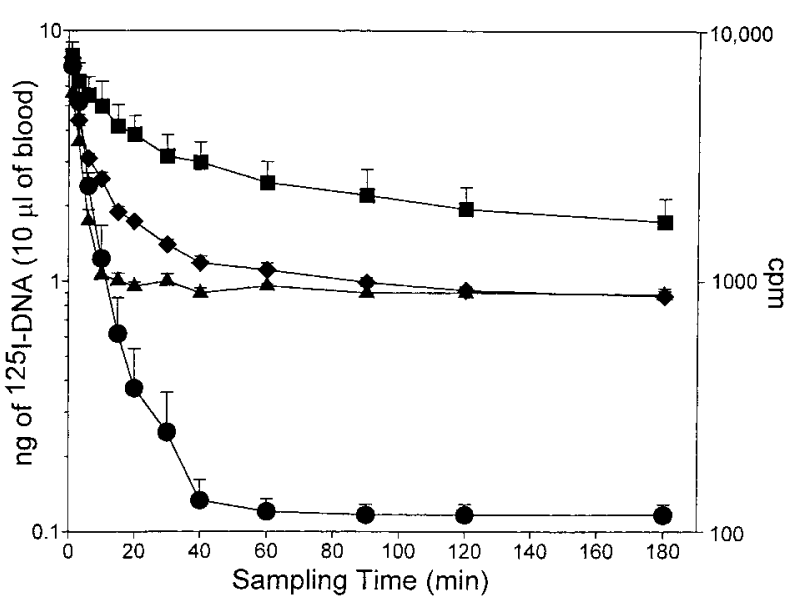

Figure 5. Pharmacokinetic analysis of cross-linked DNA co-condensates. The pharmacokinetic analysis of 50 mol \% Man9-CWK 18 PEG-VS-CWK 18 [ $\left.{ }^{125} \mathrm{I}\right] \mathrm{DNA}$ cocondensates cross-linked with 6 ( $\mathbf{\Delta})$ and 50 (O) equiv of glutaraldehydeare is compared with that of $50 \mathrm{~mol} \%$ AlkCWK ${ }^{18} /$ PEG-VS-CWK ${ }^{18}\left[{ }^{125}\right.$ I]DNA co-condensates cross-linked with 6 ( ) and 50 ( $\mathbf{a}$ ) equiv of glutaraldehyde. Each analysis represents the mean and standard deviation of three determinations.

of radioactivity in the blood over time (Figure 5). This result is consistent with metabolism in liver and release of DNA fragments into the circulation. Comparison of these results with the pharmacokinetic profile for cross-linked (6 equiv) $50 \mathrm{~mol} \% \mathrm{AlkCWK}_{18} / \mathrm{PEG}-\mathrm{VS}-\mathrm{CWK}_{18}\left[{ }^{125} \mathrm{I}\right] \mathrm{DNA}$ co-condensates, which lack a targeting ligand, established a slower $\alpha$ distribution phase followed by a prolonged elimination phase, which is also most likely the result of liver metabolism of DNA. The difference in the $\alpha t_{1 / 2}$ for 6 equiv cross-linked Man9-CWK 18 /PEG-VS-CWK 18 versus AlkCWK 18 / PEG-VS-CWK ${ }_{18}\left[{ }^{125} \mathrm{I}\right] \mathrm{DNA}$ co-condensates reflects the influence of mannose receptor-mediated uptake of the former.

By comparison, the amount of radioactivity (cpms) recovered in $10 \mu \mathrm{L}$ of blood decreased nearly 100 -fold over 40 min following iv dosing of cross-linked (50 equiv) $50 \mathrm{~mol} \%$ Man9-CWK 18 / PEG-VS-CWK ${ }_{18}\left[{ }^{125} \mathrm{I}\right] \mathrm{DNA}$ co-condensates, resulting in only trace detection of radioactivity $(<1 \%$ of dose) in blood after $60 \mathrm{~min}$ (Figure 5). The nearly complete extraction of the DNA condensates from the blood also appeared coincident in time with the liver accumulation of radioactivity (Figure 4F).

Alternatively, cross-linked (50 equiv) $50 \mathrm{~mol} \%$ AlkCWK $_{18} /$ PEG-VS-CWK 18 [ $\left.{ }^{125} \mathrm{I}\right] \mathrm{DNA}$ co-condensates had much longer $\alpha$ and $\beta$ half-lives, apparently because of non-recognition by the mannose receptor and the delay in metabolism. The amount of radioactivity (cpms) recovered in blood slowly declined to $\sim 20 \%$ of maximum over $3 \mathrm{~h}$, which occurred coincidentally with the accumulation of radioactivity in the liver (Figure 4C). The amount of radioactivity (cpms) in blood is likely intact $\left[{ }^{125} \mathrm{I}\right]$-DNA because the liver metabolism of this formulation is much slower. However, this explanation is unproven because it was not possible to uncondense cross-linked DNA condensates recovered from blood and analyze the DNA structure by gel electrophoresis. Nonetheless, fitting of the pharmacokinetic data for 50 equiv of cross-linked $\mathrm{AlkCWK}_{18} / \mathrm{PEG}$-VS$\mathrm{CWK}_{18}\left[{ }^{125} \mathrm{I}\right] \mathrm{DNA}$ co-condensates to a two-compartment model ${ }^{28}$ produced a mean residence time of $4 \mathrm{~h}$, establishing an apparent prolonged circulation for highly stabilized DNA condensates lacking a targeting ligand.

The gene expression mediated by a single iv bolus dose of $50 \mathrm{~mol} \% \mathrm{Man}$-CWK $\mathrm{CW}_{18} / \mathrm{PEG}-\mathrm{CWK}_{18}$ (VS or SS) DNA co-condensates cross-linked with either 6,15 , or 50 equiv of glutaraldehyde was evaluated in mice. When cross-linking with 6 equiv of glutaraldehyde, the hAAT expression profile over 10 days appeared coincident between formulations possessing either PEG-VS-CWK 18 or PEG-SS-CWK 18 (Figures 6A versus B). For each formulation, the days $0.5-5$ expression of $1-$ $10 \mathrm{ng} / \mathrm{mL}$ was followed by a spike of expression of $15-20 \mathrm{ng} / \mathrm{mL}$ occurring at day 6 . Comparison of these results with the hAAT expression profiles mediated by formulations cross-linking with 15 equiv of glutaraldehyde established a nearly two-fold higher level of expression at each day across the 10-day profile, with a dampening of the peak expression at day 6 (Figures $6 \mathrm{C}$ and D). A further increase in the glutaraldehyde crosslinking to 50 equiv resulted in a decrease in the overall level of hAAT expression to 3-10 ng/ $\mathrm{mL}$, with exception of the 0.5 day time point, which showed negligible expression. These results are contrasted by the gene expression mediated by cross-linked (15 equiv) $50 \mathrm{~mol} \%$ AlkCWK $_{18} /$ PEG-VS-CWK 18 DNA co-condensates (Figure 6F), which produce only background levels (1-3 ng/ML) of hAAT despite their biodistribution and retention in the liver with a $t_{1 / 2}$ of $11.6 \mathrm{~h}$ (Figure 4B).

\section{DISCUSSION}

The mannose receptor found on Kupffer cells along with the ASGP-R on hepatocytes represent 


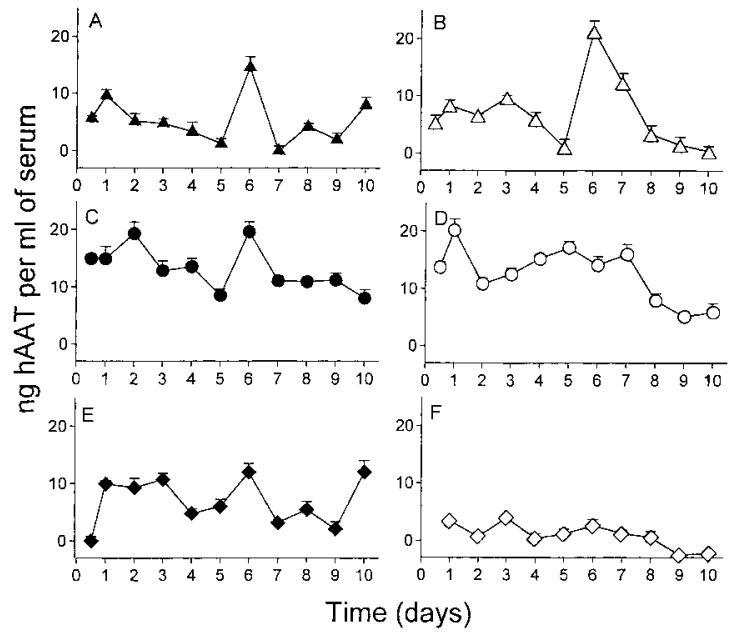

Figure 6. In vivo gene expression of cross-linked DNA co-condensates. The 10-day transient gene expression profile of hAAT in mice is compared following a single $50-\mu \mathrm{g}$ tail vein dose of a DNA formulation. Panels A and B compare the result of dosing of equiv cross-linked 50 mol \% Man9-CWK 18 / PEG-VS-CWK $_{18}$ DNA co-condensates (A) with an otherwise identical formulation (B) that substitutes PEG-SS-CWK 18 for PEG-VS-CWK 18 The results in panels $\mathrm{C}$ and $\mathrm{D}$ also compare the gene expression mediated by 50 mol \% Man9-CWK 18 PEG-CWK ${ }_{18}$ DNA co-condensates composed of PEG-VS-CWK 18 (C) and PEG-SS-CWK 18 (D) but cross-linked with 15 equiv of glutaraldehyde. Panel E illustrates the gene expression mediated by 50 equiv cross-linked 50:50 mol \% Man9$\mathrm{CWK}_{18} / \mathrm{PEG}-\mathrm{VS}-\mathrm{CWK}_{18}$ DNA co-codensates and panel $\mathrm{F}$ illustrates a control when dosing 15 equiv crosslinked 50:50 mol \% AlkCWK 18 PEG-VS-CWK 18 DNA co-condensates. Each data point represents the mean and standard error for 3 mice. Comparison of the results of panels $\mathrm{C}$ and $\mathrm{D}$ with those in $\mathrm{F}$ establish a statistical significance $(p<0.001)$ at each day.

ideal proving grounds to test hypotheses related to nonviral gene delivery systems. ${ }^{29}$ An iv dosed DNA formulation can be directed to either cell type depending on the nature of the targeting ligand (mannose versus galactose) by simultaneously blocking nonspecific binding and uptake. ${ }^{11,15,17,30,31}$ In addition to differences in monosaccharide specificity, the topography of the two receptors further differentiate their specificity for binding multivalent ligands. ${ }^{27}$ The mannose receptor is unique among C-type lectins in its preferred binding of clustered glycosides possessing mannose residues spaced by $>50 \AA$, such as would be found on a foreign organism. ${ }^{27}$ This binding preference is in contrast to that of the ASGP-R, which is composed of a cluster of three carbohydrate recognition domains that bind simultaneously to three galactose residues on a single triantennary $N$-glycan spaced by $\sim 20 \AA$. $^{32}$

The use of a LMW high-mannose glycopeptide along with a PEG-peptide led to the formulation of DNA co-condensates that shield the DNA surface charge without masking the ligand recognition. The underlying carbohydrate scaffold of the Man9 $N$-glycan apparently extends the terminal mannose residues $\sim 20 \AA$ from the surface ${ }^{33}$ of the DNA condensate so that the ligand is no longer sterically blocked by $5 \mathrm{kDa}$ PEG chains and can be recognized by the mannose receptor.

In contrast to the ASGP-R, which only required $2 \mathrm{~mol} \%$ triantennary glycopeptide to mediate maximal $(80 \%)$ targeting selectivity to hepatocytes, ${ }^{17}$ optimal Kupffer cell targeting required $50 \mathrm{~mol} \% \mathrm{Man}-\mathrm{CWK}_{18}$. This result is understandable considering the differences in the binding site topography and ligand spacing requirements of the two receptors. ${ }^{27,32}$ This result differs from the finding of Ferkol et al. who reported mannose receptor targeting of DNA condensates to Kupffer cells or lung macrophages using 1\% mannosylated HMW polylysine, although the cell-type targeting selectivity was not measured. ${ }^{9,10}$ Alternatively, the data presented here agrees more closely with the results Nishikawa et al. who found that a mannosylated polylysine $(29 \mathrm{kDa})$ possessing 11 mannose residues per polylysine chain was able to mediate $80 \%$ targeting to Kupffer cells, ${ }^{11}$ even without the use of PEG to block nonspecific targeting.

An objective of the present study was to examine the consequence of increasing the glutaraldehyde cross-linking on DNA co-condensates. Varying this parameter had little effect on surface charge but led to a progressive increase in the particle size (Table 1, E, H-J) resulting from a second $(5-15 \%)$ larger $(1 \mu \mathrm{m})$ population of DNA co-condensates. These was no difference in the Kupffer cell targeting selectivity for DNA condensates cross-linked with either 15 or 50 equiv of glutaraldehyde (Figure 2, F versus J), even though the percentage of dose targeted to the spleen increased to $30 \%$ at 50 equiv cross-linking (Figure 3C). These findings differ from those of Nishikawa et al. who reported $<10 \%$ lung or spleen targeting for mannosylated polylysine DNA condensates despite a particle size of $220 \mathrm{~nm}$ and a positive zeta potential. ${ }^{11}$ Likewise, Ferkol et al. reported that small $(<20 \mathrm{~nm})$ mannosylated polylysine DNA condensates preferentially targeted to spleen versus liver but 
were unable to demonstrate that this preference was due to mannose receptor-mediated gene delivery by competitive inhibition. ${ }^{9,10}$ Results from the present study suggest that spleen targeting is most likely related to the particle size and not the result of specific binding to the mannose receptor on spleen macrophages because cross-linked (50 equiv) $\mathrm{AlkCWK}_{18} / \mathrm{PEG-}$ $\mathrm{CWK}_{18}$ DNA co-condensates also distributed to spleen to a comparable degree.

Previously we found a difference in the in vitro gene transfer efficiency of PEG-SS-CWK 18 and PEG-VS-CWK ${ }_{18}$ DNA condensates resulting from reduction of the disulfide bond of the former during a 5 -h transfection. ${ }^{26}$ In the present study, a similar comparison of the in vivo performance of both PEG-peptides established no difference in the cell-type specific targeting, metabolic half-life, or transient gene expression profile. The disulfide bond in PEG-SS-CWK 18 is apparently resistant to reduction during circulation because the premature loss of PEG would most certainly perturb the ratio of hepatocyte and Kupffer cell targeting. It is clear, however, that PEG is an essential component of a gene delivery carrier to block nonspecific protein binding to electropositive DNA condensates resulting in lung targeting. ${ }^{15,30,31,34}$

The ability to control the metabolic half-life of DNA co-condensates by changing the glutaraldehyde cross-linking level is a unique feature of this DNA formulation. The mechanism by which glutaraldehyde cross-linking delays DNA metabolism is most likely related to either caging of the DNA to protect it from DNase ${ }^{35}$ or chemical masking of the peptide backbone of PEG-CWK ${ }_{18}$ and Man9-CWK 18 from proteases by derivatization of the lysine side chains. ${ }^{23}$ The results presented in Figure 4 indicate that increasing the glutaraldehyde cross-linking from 6 to 15 equiv nearly doubles the $t_{1 / 2}$ from 3.7 to $6 \mathrm{~h}$ and similarly influences the level of transient gene expression (Figures 6A, versus 6C). The production of gene product in Kupffer cells appears to be strictly dependent on the presence of a targeting ligand because a control formulation lacking the high-mannose $N$-glycan distributed nonspecifically between hepatocytes and Kupffer cells (Figure 2B) and possessed a $t_{1 / 2}$ of $11.6 \mathrm{~h}$ (Figure 4B) but failed to mediate gene expression (Figure 6F).

At very high cross-linking levels (50 equiv), the half-life was extended to 2-3 days but the level of gene expression each day was lower (Figure 6E). This result is similar to that observed when studying glutaraldehyde cross-linked DNA condensates in vitro ${ }^{17}$ and might be expected if crosslinked DNA condensates only release plasmid DNA slowly inside the target cell. The ability to control the intracellular release rate of DNA may result in the ability to control the duration of gene expression.

An important and unexpected consequence of glutaraldehyde cross-linking was its influence on the apparent pharmacokinetic profile of DNA formulations. The long pharmacokinetic half-life of cross-linked (50 equiv) $50 \mathrm{~mol} \% \mathrm{AlkCWK}_{18} /$ PEG-VS-CWK 18 DNA co-condensates (Figure 5) in conjunction with the delayed liver accumulation over $3 \mathrm{~h}$ (Figure 4C, inset) suggest stabilized DNA co-condensate possessing at least $50 \mathrm{~mol} \%$ PEG remain in the circulation and are only slowly captured by the liver. This result has implications for the design of DNA condensates that target to peripheral tissues. ${ }^{30}$

In conclusion, we examined the function of a LMW peptide carrier molecules to facilitate specific targeting of DNA to Kupffer cells in vivo and protect the targeted DNA from premature metabolism. The results indicate that increasing DNA condensate cross-linking decreases DNA metabolism and has an overall effect of increasing the level of gene expression. At very high crosslinking levels, the transient gene expression is suppressed, but this could also lead to an increase in the duration of gene expression. This hypothesis must be systematically explored in a future study.

\section{ACKNOWLEDGMENTS}

The authors acknowledge financial support from NIH GM48049 and from Selective Genetics Inc.

\section{REFERENCES}

1. Nishikawa M, Yamauchi M, Morimoto K, Ishida E, Takakura Y, Hashida M. 2000. Heptocyte-targeted in vivo gene expression by intravenous injection of plasmid DNA complexed with synthetic multifunctional gene delivery system. Gene Ther 7:548-555.

2. Plank C, Zatloukal K, Cotton M, Mechtler K, Wagner E. 1992. Gene transfer into hepatocytes using asialoglycoprotein receptor mediated endocytosis of DNA complexed with an artificial tetraantennary galactose ligand. Bioconj Chem 3: $533-539$. 
3. Wu GY, Wu CH. 1988. Receptor-mediated gene delivery and expression in vivo. $\mathrm{J}$ Biol Chem 263:14621-14624.

4. Perales JC, Ferkol T, Beegen H, Ratnoff OD, Hanson RW. 1994. Gene transfer in vivo: Sustained expression and regulation of genes introduced into the liver by receptor-targeted uptake. Proc Natl Acad Sci USA 91:4086-4090.

5. Pouton CW, Seymour LW. 1998. Key issues in nonviral gene delivery. Adv Drug Del Rev 34:3-19.

6. Chowdhury $\mathrm{NR}, \mathrm{Wu} \mathrm{CH}, \mathrm{Wu}$ GY, Yerneni PC, Bommineni VR, Chowdhury JR. 1993. Fate of DNA targeted to the liver by asialoglycoprotein receptormediated endocytosis in vivo. Prolonged persistence in cytoplasmic vesicles after partial hepatectomy. J Biol Chem 268:11265-11271.

7. Laurent N, Coninck SWD, Mihaylova E, Leontieva E, Wanier-Pirotte MT, Wattiaux R, Jadot M. 1999. Uptake by rate liver and intracellular fate of plasmid DNA complexed with poly-L-lysine or poly-D-lysine. FEBS Lett 443:61-65.

8. Ziady AG, Ferkol T, Dawson DV, Perlmutter DH, Davis PB. 1999. Chain length of the polylysine in receptor-targeted gene transfer complexes affects duration of reporter gene expression both in vitro and in vivo. J Biol Chem 274:4908-4916.

9. Ferkol T, Perales JC, Mularo F, Hanson RW. 1996. Receptor-mediated gene transfer into macrophages. Proc Natl Acad Sci USA 93:101-105.

10. Ferkol T, Mularo F, Hilliard J, Lodish S, Perales JC, Ziady A, Konstan M. 1998. Transfer of the human alpha-1-antitrypsin gene into pulmonary macrophages in vivo. Am J Respir Cell Mol Biol 18:591-601.

11. Nishikawa M, Takemura S, Yamashita F, Takakura Y, Meijer DK, Hashida M, Swart PJ. 2000. Pharmacokinetic and in vivo gene transfer of plasmid DNA complexed with mannosylated poly(L-lysine) in mice. J Drug Target 8:29-38.

12. Wadhwa MS, Knoell DL, Young AP, Rice KG. 1995. Targeted gene delivery with a low molecular weight glycopeptide carrier. Bioconj Chem 6: 283-291.

13. Smith LC, Duguid J, Wadhwa MS, Logan MJ, Tung CH, Edwards V, Sparrow JT. 1998. Synthetic peptide-based DNA complexes for nonviral gene delivery. Adv Drug Delivery Rev 30:115-131.

14. Plank C, Tang MX, Wolfe AR, Szoka FC Jr. 1999. Branched cationic peptides for gene delivery: Role of type and number of cationic residues in formation and in vitro activity of DNA polyplexes. Human Gene Ther 10:319-332.

15. Kwoh DY, Coffin CC, Lollo CP, Jovenal J, Banaszczyk MG, Mullen P, Phillips A, Amini A, Fabrycki J, Bartholomew RM, Brostoff SW, Carlo DJ. 1999. Stabilization of poly-L-lysine/DNA polyplexes for in vivo gene delivery to the liver. Biochim Biophys Acta 1444:171-190.
16. Nishikawa M, Takemura S, Takakura Y, Hashida M. 1998. Targeted delivery of plasmid DNA to hepatocytes in vivo: Optimization of the pharmacokinetics of plasmid DNA/galactosylated poly (L-lysine) complexes by controlling their physicochemical properties. J Pharm Exp Ther 287:404415.

17. Collard WT, Evers DL, McKenzie DL, Rice KG. 2000. Synthesis of homogenous glycopeptides and their utility as DNA condensing agents. Carbohydr Res 223:176-184.

18. Kwok KY, Adami RC, Hester KC, Park Y, Thomas S, Rice KG. 2000. Strategies for maintaining the particle size of peptide DNA condensates following freeze-drying. Int J Pharm 203:8188.

19. Hickman MA, Malone RW, Lehmann-Bruinsma K, Sih TR, Knoell D, Szoka FC, Walzem R, Carlson DM, Powell JS. 1994. Gene expression following direct injection of DNA into liver. Human Gene Ther 5:1477-1483.

20. Terebesi J, Kwok KY, Rice KG. 1998. Iodinated plasmid DNA as a tool for studying gene delivery. Anal Biochem 263:120-123.

21. Wadhwa MS, Collard WT, Adami RC, McKenzie DL, Rice KG. 1997. Peptide-mediated gene delivery: Influence of peptide structure on gene expression. Bioconj Chem 8:81-88.

22. Evers DL, Hung RL, Thomas VH, Rice KG. 1998. Preparative purification of a high-mannose type $N$-glycan from soy bean agglutinin by hydrazinolysis and tyrosinamide derivatization. Anal Biochem 265:313-316.

23. Adami RC, Rice KG. 1999. Metabolic stability of glutaraldehyde cross-linked peptide DNA condensates. J Pharm Sci 88:739-746.

24. Chiu MH, Thomas VH, Stubbs HJ, Rice KG. 1995. Tissue targeting of multivalent Le(x)-terminated $N$-linked oligosaccharides in mice. $\mathrm{J}$ Biol Chem 270:24024-24031.

25. Michalski JP, McCombs CC, Sheth S, McCarthy M, deShazo R. 1985. A modified double antibody sandwich enzyme-linked immunosorbent assay for measurement of alpha-1 antitrypsin in biologic fluids. J Immunol Meth 83:101-112.

26. Kwok KY, McKenzie DL, Evers DL, Rice KG. 1999. Formulation of highly soluble poly(ethylene glycol)peptide DNA condensates. J Pharm Sci 88:9961003.

27. Taylor ME, Drickamer K. 1993. Structural requirements for high affinity binding of complex ligands by the macrophage mannose receptor. J Biol Chem 268:399-404.

28. Wagner JG. 1975. Fundamentals of clinical pharmacokinetics. (Drug Intelligence Publications, Hamilton, IL).

29. Takakura Y, Hashida M. 1998. Pharmacokinetics of macromolecules and synthetic gene delivery 
systems. Self-assembling complexes for gene delivery: From laboratory to clinical trial, pp 296-306.

30. Ogris M, Brunner S, Schuller S, Kircheis R, Wagner E. 1999. PEGylated DNA transferin-PEI complexes: Reduced interaction with blood components, extended circulation in blood and potential of systemic gene delivery. Gene Ther 6:595-605.

31. Dash PR, Read ML, Fisher KD, Howard KA, Wolfert M, Oupicky D, Subr V, Strohalm J, Ulbrich K, Seymour LW. 2000. Decreased binding to proteins and cells of polymeric gene delivery vectors surface modified with a multivalent hydrophilic polymer and retargeting through attachment of transferrin. J Biol Chem 275:3793-3802.

32. Rice KG, Weisz OA, Barthel T, Lee RT, Lee YC. 1990. Defined geometry of binding between trian tennary glycopeptide and the asialoglycoprotein receptor of rat heptocytes. J Biol Chem 265:18429_ 18434.

33. Rice KG, Wu RG, Brand L, Lee YC. 1991. Interterminal distance and flexibility of a triantennary glycopeptide as measured by resonance energy transfer. Biochemistry 30:6646-6655.

34. Toncheva V, Wolfert MA, Dash PR, Oupicky D, Ulbrich K, Seymour LW, Schacht EH. 1998. Novel vectors for gene delivery formed by self-assembly of DNA with poly(L-lysine) grafted with hydrophilic polymers. Biochim Biophys Acta 1380:354-368.

35. Trubetskoy VS, Loomis A, Slattum PM, Hagstrom JE, Budker VG, Wolff JA. 1999. Caged DNA does not aggregate in high ionic strength solutions. Bioconj Chem 10:624-628. 